\title{
Cortical and cerebellar activation induced by reflexive and voluntary saccades
}

\author{
Caroline K. L. Schraa-Tam • \\ Phillippus van Broekhoven · Josef N. van der Geest • \\ Maarten A. Frens • Marion Smits • Aad van der Lugt
}

Received: 18 April 2008 / Accepted: 2 September 2008 / Published online: 17 September 2008

(C) The Author(s) 2008. This article is published with open access at Springerlink.com

\begin{abstract}
Reflexive saccades are driven by visual stimulation whereas voluntary saccades require volitional control. Behavioral and lesional studies suggest that there are two separate mechanisms involved in the generation of these two types of saccades. This study investigated differences in cerebral and cerebellar activation between reflexive and self-paced voluntary saccadic eye movements using functional magnetic resonance imaging. In two experiments (whole brain and cerebellum) using the same paradigm, differences in brain activations induced by reflexive and self-paced voluntary saccades were assessed. Direct comparison of the activation patterns showed that the frontal eye fields, parietal eye field, the motion-sensitive area (MT/ V5), the precuneus (V6), and the angular and the cingulate gyri were more activated in reflexive saccades than in voluntary saccades. No significant difference in activation was found in the cerebellum. Our results suggest that the alleged separate mechanisms for saccadic control of reflexive and self-paced voluntary are mainly observed in cerebral rather than cerebellar areas.
\end{abstract}

C. K. L. Schraa-Tam and P. van Broekhoven contributed equally to this study.

C. K. L. Schraa-Tam · J. N. van der Geest · M. Smits ·

A. van der Lugt $(\bowtie)$

Department of Radiology, Erasmus MC,

PO Box 2040, 3000 CA Rotterdam, The Netherlands

e-mail: a.vanderlugt@erasmusmc.nl

P. van Broekhoven - J. N. van der Geest · M. A. Frens

Department of Neuroscience,

Erasmus MC, Rotterdam, The Netherlands
Keywords Functional magnetic resonance imaging · Reflexive saccades · Voluntary saccades

\section{Introduction}

Saccades are fast rotatory eye movements that serve to move the eyes as quickly as possible, so that an object of interest is projected onto the fovea where it can be visually processed in detail (Schall 1995; Hayakawa et al. 2002; Schiller and Tehovnik 2005; Amlot and Walker 2006). Saccades can be classified into two broad categories: reflexive and higher-order saccades. Reflexive saccades are saccades toward suddenly appearing targets and are described as reflexive or targeting saccades. Higher-order saccades have a more volitional nature and include voluntary, memoryguided and delayed saccades. Voluntary saccades are made with a cognitive judgment in order to determine when and where to move gaze (Straube and Deubel 1995; Leigh and Zee 1999; Walker et al. 2000).

The neurophysiological circuit that drives saccadic eye movements includes several distinct regions of the brain (Leigh and Zee 1999). The mesencephalic and the pontine reticular formations of the brainstem encode the motor signals that drive the eye muscles. The superior colliculus encodes the direction and amplitude of the saccadic eye movements (Leigh and Zee 1999). Several cortical brain areas, such as the frontal eye fields (FEF), the supplementary eye fields (SEF), the parietal eye fields (PEF), and the motion sensitive area (MT/V5), are also known to be involved in saccadic generation. Furthermore, the cerebellum is involved in maintaining saccadic accuracy (Leigh and Zee 1999). Specific areas of the human cerebellum, such as lobules VI and VII and the fastigial nucleus, have been implicated in maintaining saccadic accuracy (Zee 
et al. 1976; Straube and Deubel 1995). Patients with cerebellar lesions often show inaccurate saccades (known as saccadic dysmetria) that do not resolve over time (Straube and Deubel 1995).

Several functional magnetic resonance imaging (fMRI) and positron emission tomography (PET) imaging studies have shown activation in the human cerebellum during saccadic eye movements (Desmurget et al. 1998; Dieterich et al. 2000; Hayakawa et al. 2002; Nitschke et al. 2004). For instance, Hayakawa et al. observed activity in the posterior vermis and the bilateral hemispheres of the cerebellum when subjects made saccades between two stationary targets (Hayakawa et al. 2002).

It has been suggested that there are two separate and largely independent mechanisms involved in the generation of reflexive saccades and voluntary saccades (Deubel 1995). Mort et al. aimed to compare the cortical activation patterns induced by these two types of saccades with fMRI (Mort et al. 2003). In their paradigm, reflexive saccades were evoked by flashing a peripheral spot to the left or the right of the fixation spot. Voluntary saccades were evoked by means of an arrow cue as an indicator to the observer to change their point of gaze to a dot pointed at by the arrow. Their results suggested that FEF and PEF were more activated during voluntary saccades and that the angular gyrus and the precuneus were more activated during reflexive saccades (Mort et al. 2003). Furthermore, behavioral studies showed that modification of the amplitudes of reflexive saccades in a saccade adaptation paradigm (McLaughlin 1967) does not influence the amplitudes of voluntary saccades, and vice versa (Erkelens and Hulleman 1993; Gaveau et al. 2005; Alahyane et al. 2007). The cerebellum is an important brain structure in saccadic gain control (Ron and Robinson 1973; Straube and Deubel 1995; Desmurget et al. 1998; Barash et al. 1999; Straube et al. 2001). Desmurget et al. (2000) demonstrated that the oculomotor vermis of the cerebellum is activated in a saccade adaptation paradigm. The results of the behavioral studies suggest that the cerebellum might also be involved in a different way in maintaining the accuracy of reflexive and voluntary saccades.

In the present study, fMRI was used to investigate putative differences in cerebral and cerebellar activation patterns between reflexive and self-paced voluntary saccadic eye movements. We performed two experiments using the same experimental paradigm. The first experiment aimed to assess cerebral activations of saccadic eye movements and to compare the results with data from existing literature. The second experiment focused on the cerebellum, specifically obtaining more detailed activation within this brain structure. We hypothesized that the differences between reflexive and self-paced voluntary saccadic eye movements might be reflected by differences in cerebral as well as in cerebellar activation patterns.

\section{Materials and methods}

\section{Subjects}

Written informed consent was obtained from each participant prior to the study, which was approved by the Institutional Review Board. Subjects could participate in either one or both of the two experiments that were performed: whole brain and cerebellum. A total of 26 healthy volunteers (13 men, 13 women; average age 26.7 years, range 22-37 years) participated in the whole brain experiment, and 26 healthy volunteers ( 15 men, 11 women; average age 26.7 years, range $22-37$ years) participated in the cerebellum experiment. Ten of these subjects participated in both experiments. None of the subjects had any known neurological or visual defects other than minor refractive anomalies. None of the subjects wore spectacle correction during the experiments, as minor refractive anomalies could be adjusted for by the goggle system that was used to display the stimuli. All subjects reported good visual acuity during the experiment.

\section{Data acquisition}

For each subject the images were acquired on a 1.5T MRI scanner (Signa CV/I; General Electric, Milwaukee, USA) using a dedicated 8-channel head coil. For the anatomical image, a 3D high-resolution inversion recovery FSPGR T1weighted sequence covering the entire brain was acquired (repetition time (TR)/echo time (TE)/inversion time (TI)/9.99/ $2 / 400 \mathrm{~ms}$, flip angle $20^{\circ}, 320 \times 224$ matrix with a rectangular field-of-view of $22 \mathrm{~cm}, 1.2 \mathrm{~mm}$ slice thickness with no gap; parallel imaging factor of 2). Acquisition time was $5 \mathrm{~min}$.

\section{Functional imaging}

For functional imaging, a single-shot gradient-echo echoplanar imaging (EPI) sequence in transverse orientation was used in each study that is sensitive to blood oxygenation level dependent (BOLD) contrast. For the whole brain experiment, the imaging volume covered the entire brain (TR/TE 4,500/50 ms, $64 \times 64$ matrix with a rectangular field-of-view of $22 \mathrm{~cm}, 2.5 \mathrm{~mm}$ slice thickness, 48 contiguous slices; voxel size of $2.5 \times 3.5 \times 3.5 \mathrm{~mm}^{3}$ ). Acquisition time was 10:03 min per scanning session (including $18 \mathrm{~s}$ of dummy scans that were discarded). For the cerebellum experiment, the imaging volume only covered the whole cerebellum with higher spatial and temporal resolution (TR/TE 3,000/50 ms, $96 \times 96$ matrix with a rectangular field-of-view of $24 \mathrm{~cm}, 2.5 \mathrm{~mm}$ slice thickness, 18 contiguous slices; voxel size of $2.5 \times 2.5 \times 2.5 \mathrm{~mm}^{3}$ ). Acquisition time was 10:00 min per scanning session (including $12 \mathrm{~s}$ of dummy scans that were discarded). 
Eye tracking

Eye movements (monocular, left eye) were registered continuously with the Real Eye RE-4601 Imaging System (Avotec Inc., Stuart, FA, USA) with a $60 \mathrm{~Hz}$ sampling rate. Online monitoring of eye movements and recording was done with the iViewX Eye Tracking System (SensoMotoric Instruments, Teltow, Germany). The system was calibrated before each scan session with the built-in 3-by-3 point calibration routine.

\section{Stimulus paradigm}

The experiments were performed in near darkness. The visual stimuli were binocularly presented by means of a goggle-based system (Silent Vision SV-7021 Fiber Optic Visual System; Avotec Inc.). The optical components were mounted on top of the head coil. Screen resolution was $1,024 \times 768$ pixels and the refresh rate was $60 \mathrm{~Hz}$.

The visual stimulation was exactly the same for both experiments (whole brain and cerebellum), and consisted of three different visual displays, corresponding to three experimental conditions. In all three displays, three horizontally aligned dots $\left(0.9^{\circ}\right.$ of visual angle in diameter) were presented on a dark background. The horizontal separation between the dots was $9^{\circ}$, and the central dot was centered in the subject's visual field-of-view. The overall luminance was $0.43 \mathrm{~cd} / \mathrm{m}^{2}$.

In the fixation condition (baseline), the central dot was yellow, and the two peripheral dots were gray. Subjects were instructed to look at the yellow dot continuously. In the first active condition (reflexive saccades), the central dot and one of the peripheral dots were gray, and the other one was yellow. The two peripheral dots were intermittently yellow with a random interval between 1 and $2 \mathrm{~s}$. In this condition saccade pace was therefore imposed by the other peripheral dot turning yellow.

In the second active condition (voluntary saccades), the central dot was gray, and both peripheral dots were yellow. Subjects were instructed to change their point of gaze between the two dots about every second, thus performing self-paced voluntary saccadic eye movements.

Task design

An experiment consisted of a block design in which the baseline condition [fixation $(\mathrm{F})$ ] and one of the two active conditions [reflexive (R) saccades and voluntary (V) saccades] were presented in alternation. The sequence of conditions started and ended with the baseline condition. The order of the two active conditions was switched halfway through the experiment [F-R-F-V...F-R-F-V-F(switch)-V-F-R...F-V-F-R-F].
In the whole brain experiment, an active condition lasted for $31.5 \mathrm{~s}$ during which seven volumes were acquired. The baseline (fixation) condition lasted either $13.5 \mathrm{~s}$ (six times) or $18 \mathrm{~s}$ (seven times) during which three or four volumes, respectively, were acquired. Each of the two active conditions was presented six times and the baseline condition was presented 13 times in total. In the cerebellum experiment, each active condition lasted for $24 \mathrm{~s}$ during which time eight volumes were acquired. The baseline condition lasted for $12 \mathrm{~s}$ during which four volumes were acquired. Each of the two active conditions was presented eight times and the baseline condition was presented 17 times.

Analysis

\section{Eye movements}

The eye movement recordings were analyzed offline. Saccadic eye movements were extracted semi-automatically using an eye velocity criterion of $30 \%$ and checked manually. The total number of saccades was counted, and the average number of saccades per second was calculated for each subject, for each of the three conditions and for each of the two experiments. Paired $t$ tests were used to assess differences between the conditions for significance.

Subjects were excluded from the analyses if they showed inadequate eye movement behavior, such as not looking at the yellow dot continuously or making more than one saccade per second in the voluntary condition. Subjects, in whom eye tracking failed due to technical problems, were also excluded.

\section{Functional imaging data}

The functional imaging data were analyzed using statistical parametric mapping software (SPM 2, distributed by the Wellcome Department of Cognitive Neurology, University College London, UK) implemented in MATLAB (Version 6.5, Mathworks, Sherborn, MA, USA). For both studies, motion correction and co-registration were done according to the methodology provided by SPM2 (Tzourio-Mazoyer et al. 2002). The time-series of images were realigned using a least square approach and a six parameter spatial transformation. The central image in the time-series was the reference to which all subsequent images were realigned (Friston et al. 1995). Motion parameters were checked for each subject to ascertain that no excessive motion $(>3 \mathrm{~mm}$ translation or $>1.5^{\circ}$ rotation) has occurred. None of the scan sessions had to be discarded due to excessive motion.

Brain volumes were normalized to the standard space defined by the Montreal Neurological Institute (MNI) template. The normalized data had a resolution of $2 \times 2 \times 2 \mathrm{~mm}^{3}$ and were spatially smoothed with a 3D 
isotropic Gaussian kernel, with a full width half maximum of $8 \mathrm{~mm}$ for the whole brain experiment and $6 \mathrm{~mm}$ for the cerebellum experiment.

Statistical parametric maps were calculated for each subject. Movement parameters resulting from the realignment pre-processing were included as regressors of no interest to further reduce motion artifacts. The model was estimated with a high-pass filter with a cut-off period of $128 \mathrm{~s}$. For each subject and for each experiment, t-contrast maps were calculated between each of the two active condition and the baseline condition [(active $\mathrm{reflexive}>$ baseline) and (active $\mathrm{voluntary}>$ baseline)] and between the two active conditions.

The individual t-contrast maps were used for second level random effects (group) analysis. One sample $t$ tests were performed for each of the conditions and each of the experiments separately: (active $\mathrm{reflexive}>$ baseline) and (active $_{\text {voluntary }}>$ baseline). To investigate the differences in brain activation between the reflexive and the voluntary saccade conditions directly we used an analysis of covariance (ANCOVA) in which we compared active reflexive $_{\text {ver- }}$

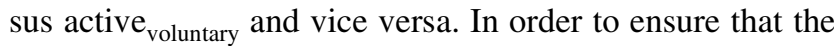
differences in brain activation between these two active conditions are not caused by differences in the number of saccades made during the active condition, for each subject we counted the numbers of saccades made in the active conditions of the behavioral experiments $\left(N_{\text {reflexive }}\right.$ and $\left.N_{\text {voluntary }}\right)$. From these numbers we obtained the ratio $\left[\left(N_{\text {reflexive }}-N_{\text {voluntary }}\right) /\left(N_{\text {reflexive }}+N_{\text {voluntary }}\right)\right]$ for each active condition, which was entered as a regressor of no interest. All tests were thresholded at $P<0.05$ with false discovery rate (FDR) correction for multiple comparisons and at a minimum cluster size of 10 voxels.

Reporting of activation is focused on the brain areas that are involved in saccadic eye movements, namely the FEF, SEF, PEF, MT/V5, precuneus (V6), cingular and angular gyri, PVA/V1 and the cerebellum. In the whole brain experiment we focused on cerebral activations, whereas the cerebellum study allowed for a more detailed assessment of cerebellar activation.

\section{Results}

Eye movements

Inspection of the eye movement behavioral data showed that eye tracking failed in four subjects and that 12 subjects did not perform properly during the experiments (seven subjects in the whole brain experiment, and five subjects in the cerebellum experiment): four subjects made too many saccades in the voluntary conditions and eight subjects did not look at the yellow dot continuously. These 16 subjects were excluded from further analyses leaving 18 subjects for each of the two experiments; nine of these subjects participated in both experiments.

For the whole brain experiment, the average $( \pm \mathrm{SD})$ number of saccades per second was $0.11 \pm 0.04$ for the fixation condition, $0.71 \pm 0.05$ for the reflexive condition and $0.81 \pm 0.15$ for the voluntary condition. For the cerebellum experiment, the average $( \pm \mathrm{SD})$ number of saccades per second was $0.09 \pm 0.05$ for the fixation condition, $0.70 \pm 0.07$ for the reflexive condition and $0.72 \pm 0.09$ for the voluntary condition.

As expected, the number of saccades per second was significantly higher in each of the active conditions than in the baseline condition for both the whole brain experiment and the cerebellum experiment. For the whole brain experiment, the number of saccades per second made in the voluntary condition was higher than in the reflexive condition $(P=0.012)$. In the cerebellum experiment subjects made an equal number of saccades in both active conditions $(P=0.55)$. In both experiments, the average number of saccades per second made in the reflexive condition matched the number of target onsets ( 0.7 per second). None of the subjects made saccades toward the target before it turned yellow in the reflexive condition.

\section{fMRI activation}

The results of the random effects group analysis for the whole brain experiment and for the cerebellum experiment are shown in Tables 1 and 2. In the cerebellum experiment no significant activation was found at a threshold of $P<0.05$ with FDR correction. Therefore, we used a more lenient statistical threshold of $P<0.05$ corrected for multiple comparisons at cluster level and with a minimum cluster size of 10 voxels.

\section{Reflexive saccades}

Analysis of the reflexive saccade condition for the whole brain experiment revealed bilateral activation in the precentral gyrus (frontal eye fields, FEF), in the superior parietal gyrus (parietal eye fields, PEF) and in the middle temporal gyrus (MT/V5) (Fig. 1). Unilateral activation was found in the left angular gyrus.

The cerebellum experiment revealed bilateral activation in lobule VI and unilaterally in crus I on the left (Fig. 2). Activity was also found in vermis VI and VII.

\section{Voluntary saccades}

Analysis of the voluntary saccade condition for the whole brain experiment revealed bilateral activation in the precentral gyrus (FEF) and unilateral activation in the left inferior parietal gyrus (PEF) (Fig. 3). 
Table 1 Areas of activation (reflexive saccades > fixation) with cluster size, maximum $t$ value within the cluster, MNI coordinates of the maximum $t$ value, anatomic labels, percentage of cluster size and functional area

\begin{tabular}{|c|c|c|c|c|c|c|c|c|}
\hline \multicolumn{9}{|c|}{ Whole brain study: reflexive } \\
\hline \multirow{2}{*}{$\overline{\text { Cluster size }}$} & \multirow[t]{2}{*}{$T$ value } & \multicolumn{3}{|c|}{ MNI coordinate $(\mathrm{mm})$} & \multirow[t]{2}{*}{ Anatomic area } & \multirow[t]{2}{*}{ Side } & \multirow[t]{2}{*}{$\%^{\mathrm{a}}$} & \multirow[t]{2}{*}{ Functional area } \\
\hline & & $x$ & $y$ & $z$ & & & & \\
\hline \multirow[t]{10}{*}{14,877} & 7.78 & 46 & -74 & -2 & Middle temporal gyrus & $\mathrm{R}$ & 4.89 & MT/V5 \\
\hline & & & & & Middle temporal gyrus & $\mathrm{L}$ & 3.6 & MT/V5 \\
\hline & & & & & Lingual and calcarine gyri & $\mathrm{L}$ & 31.33 & PVA/V1 \\
\hline & & & & & $\begin{array}{l}\text { Middle, inferior and superior } \\
\text { Occipital gyri, cuneus }\end{array}$ & & & \\
\hline & & & & & Lingual and calcarine gyri & $\mathrm{R}$ & 26.56 & PVA/V1 \\
\hline & & & & & $\begin{array}{l}\text { Middle, inferior and superior } \\
\text { Occipital gyri, cuneus }\end{array}$ & & & \\
\hline & & & & & Fusiform gyrus & $\mathrm{R}$ & 4.38 & \\
\hline & & & & & Fusiform gyrus & $\mathrm{L}$ & 2.65 & \\
\hline & & & & & Angular gyrus & $\mathrm{L}$ & 1.18 & Angular gyrus \\
\hline & & & & & Superior temporal gyrus & $\mathrm{L}$ & 1.01 & \\
\hline \multirow[t]{3}{*}{1,124} & 6,022 & 40 & -10 & 54 & Precentral gyrus & $\mathrm{R}$ & 51.6 & FEF \\
\hline & & & & & Postcentral gyrus & $\mathrm{R}$ & 30.78 & \\
\hline & & & & & Middle frontal gyrus & $\mathrm{R}$ & 3.2 & \\
\hline \multirow[t]{2}{*}{454} & 5.78 & -60 & -14 & 42 & Postcentral gyrus & $\mathrm{L}$ & 68.72 & \\
\hline & & & & & Precentral gyrus & $\mathrm{L}$ & 26.87 & FEF \\
\hline \multirow[t]{2}{*}{394} & 4.64 & -24 & -62 & 62 & Superior and inferior parietal gyrus & $\mathrm{L}$ & 91.11 & PEF \\
\hline & & & & & Postcentral gyrus & $\mathrm{L}$ & 2.54 & \\
\hline 99 & 4.51 & 24 & -48 & 40 & Superior and inferior parietal gyrus & $\mathrm{R}$ & 33.33 & PEF \\
\hline 146 & 4.28 & 26 & -62 & 56 & Superior parietal gyrus & $\mathrm{R}$ & 98.63 & PEF \\
\hline \multicolumn{9}{|c|}{ Cerebellum study: reflexive } \\
\hline \multirow[t]{5}{*}{409} & 7.02 & -4 & -76 & -14 & Cerebellum VI & $\mathrm{L}$ & 38.39 & Oculomotor area \\
\hline & & & & & Cerebellum VI & $\mathrm{R}$ & 20.29 & \\
\hline & & & & & Vermis VI & & 18.09 & \\
\hline & & & & & Vermis VII & & 4.16 & \\
\hline & & & & & Cerebellum crus 1 & $\mathrm{~L}$ & 2.44 & \\
\hline
\end{tabular}

All areas were thresholded at $P<0.05$ with FDR (whole brain study) or at cluster level $(P<0.05)$ corrected for multiple comparisons (cerebellum study) and with a minimum cluster size of 10 voxels

$L$ left hemisphere, $R$ right hemisphere, FEF frontal eye fields, $P E F$ parietal eye fields, MT/V5 motion-sensitive area (MT/V5), $P V A / V 1$ primary visual areas (V1)

${ }^{\text {a }}$ The unassigned areas for each cluster are not listed in the table

The cerebellum experiment revealed only unilateral activation in the right lobule VI (Fig. 4). Activity was also found in vermis VI and VII.

\section{Direct comparison between reflexive and voluntary saccades}

Results of the direct comparison between the two active (saccade) conditions are given in Table 3, and visualized in Fig. 5. When the reflexive saccade condition was compared with the voluntary saccade condition (active reflexive $>$ active $_{\text {voluntary }}$ ) for the whole brain experiment, the analysis yielded bilateral activation in the precentral gyrus (FEF), in the inferior and superior parietal gyrus (PEF), in the middle temporal gyrus (MT/V5), the precuneus (V6), and the angular and the anterior cingulate gyrus, and unilateral right activation in the posterior cingulate gyrus.

When the reflexive saccade condition was compared with the voluntary saccade condition (active $_{\text {reflexive }}>$ active $\left._{\text {voluntary }}\right)$ in the cerebellum experiment, the analysis yielded unilateral activation in the left lobule VI. This area of activation, however, was part of the large activation cluster in the fusiform gyrus, similar to that observed in the whole brain experiment. The actual part of this larger cluster being located in the left cerebellar lobule VI was less than 10 voxels.

For both the whole brain and the cerebellum experiment, no significant activation was found when the voluntary 
Table 2 Areas of activation (voluntary saccades $>$ fixation) with cluster size, maximum $t$ value within the cluster, MNI coordinates of the maximum $t$ value, anatomic labels, percentage of cluster size and functional area

\begin{tabular}{|c|c|c|c|c|c|c|c|c|}
\hline \multicolumn{9}{|c|}{ Whole brain study: voluntary } \\
\hline \multirow[t]{2}{*}{$\begin{array}{l}\text { Cluster size } \\
\text {. }\end{array}$} & \multirow[t]{2}{*}{$T$ value } & \multicolumn{3}{|c|}{ MNI coordinate $(\mathrm{mm})$} & \multirow[t]{2}{*}{ Anatomic area } & \multirow[t]{2}{*}{ Side } & \multirow[t]{2}{*}{$\%^{\mathrm{a}}$} & \multirow[t]{2}{*}{ Functional area } \\
\hline & & $x$ & $y$ & $z$ & & & & \\
\hline \multirow[t]{4}{*}{323} & 8.35 & -62 & 2 & 20 & Postcentral gyrus & $\mathrm{L}$ & 44.89 & FEF \\
\hline & & & & & Precentral gyrus & $\mathrm{L}$ & 19.81 & \\
\hline & & & & & Rolandic opercular gyrus & $\mathrm{L}$ & 16.72 & \\
\hline & & & & & Inferior frontal opercular gyrus & $\mathrm{L}$ & 14.24 & \\
\hline \multirow[t]{3}{*}{2,848} & 7.62 & -16 & -78 & 6 & $\begin{array}{l}\text { Lingual and calcarine gyri } \\
\text { Middle, inferior and superior } \\
\text { Occipital gyri, cuneus }\end{array}$ & $\mathrm{R}$ & 40.81 & PVA/V1 \\
\hline & & & & & $\begin{array}{l}\text { Lingual and calcarine gyri } \\
\text { Middle, inferior and superior } \\
\text { Occipital gyri, cuneus }\end{array}$ & $\mathrm{L}$ & 49.31 & PVA/V1 \\
\hline & & & & & Fusiform gyrus & $\mathrm{R}$ & 1.19 & \\
\hline 31 & 5.1 & -34 & -74 & -6 & Inferior and middle occipital gyri & $\mathrm{L}$ & 61.92 & PVA/V1 \\
\hline 36 & 4.94 & 28 & -84 & 24 & Middle and superior occipital gyri & $\mathrm{R}$ & 100 & PVA/V1 \\
\hline 14 & 4.37 & -28 & -50 & 52 & Inferior parietal gyrus & $\mathrm{L}$ & 100 & PEF \\
\hline \multirow[t]{3}{*}{137} & 4.32 & 56 & -8 & 44 & Precentral gyrus & $\mathrm{R}$ & 57.66 & FEF \\
\hline & & & & & Postcentral gyrus & $\mathrm{R}$ & 33.58 & \\
\hline & & & & & Middle frontal gyrus & $\mathrm{R}$ & 8.76 & \\
\hline \multicolumn{9}{|c|}{ Cerebellum study: voluntary } \\
\hline \multirow[t]{3}{*}{48} & 4.65 & 6 & -76 & -20 & Cerebellum VI & $\mathrm{R}$ & 70.83 & Oculomotor area \\
\hline & & & & & Vermis VI & & 20.83 & \\
\hline & & & & & Vermis VII & & 8.33 & \\
\hline
\end{tabular}

All areas were thresholded at $P<0.05$ with FDR (whole brain study) or at cluster level $(P<0.05)$ corrected for multiple comparisons (cerebellum study) and with a minimum cluster size of 10 voxels

$L$ left hemisphere, $R$ right hemisphere, $F E F$ frontal eye fields, $P E F$ parietal eye fields, $M T / V 5$ motion-sensitive area (MT/V5), $P V A / V 1$ primary visual areas (V1)

a The unassigned areas for each cluster are not listed in the table

Fig. 1 Reflexive saccade eye movement: activation clusters in the whole brain study for reflexive saccades versus fixation. All areas were thresholded at $P<0.05$ with FDR correction for multiple comparisons and with a minimum cluster size of 10 voxels. (Labels $A$ FEF, $B$ PEF $C$ MT/V5)

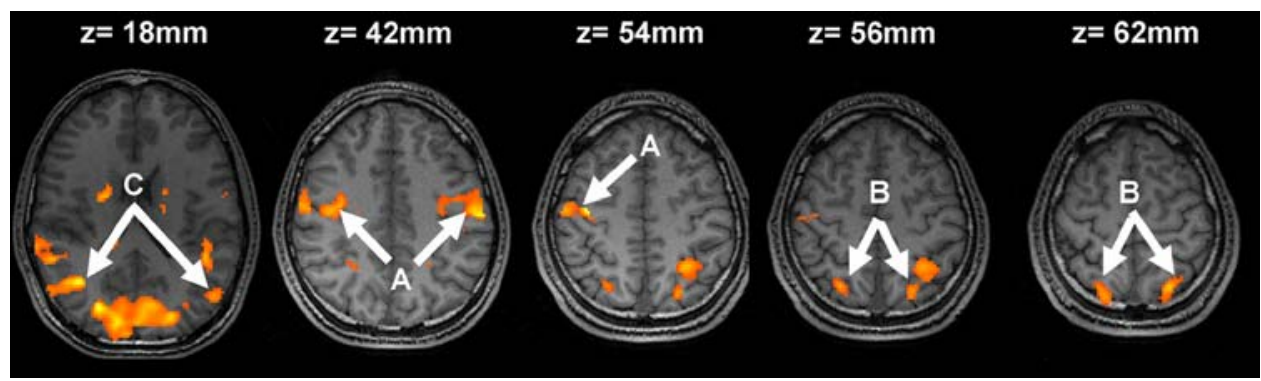

saccade condition was compared with the reflexive saccade condition.

A summary of the results is presented in Table 4.

\section{Discussion}

This study investigated differences in brain activation patterns between reflexive and voluntary saccadic eye movements. These two types of saccades were compared in two different experiments in which we looked for cerebral activation and for specific activation in the cerebellum.

Numerous functional imaging studies have investigated brain activation related to reflexive or voluntary saccades separately. PET studies have shown activation during reflexive saccades in FEF (Anderson et al. 1994; Sweeney et al. 1996), PEF (Anderson et al. 1994), cerebellum, striate cortex and posterior temporal cortex (Sweeney et al. 1996). fMRI studies have also shown activation in FEF (Petit et al. 1997; Luna et al. 1998; Muri et al. 1998; Berman et al. 


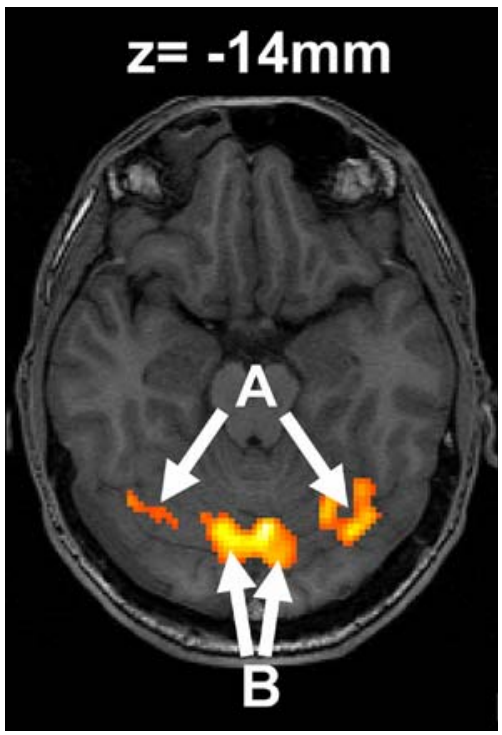

Fig. 2 Reflexive saccade eye movement: activation clusters in the cerebellum study. All areas were thresholded at $P<0.05$ with correction for multiple comparisons at cluster level and with a minimum cluster size of 10 voxels. (Labels $A$ cerebellum lobule VI, $B$ vermis VI and VII)

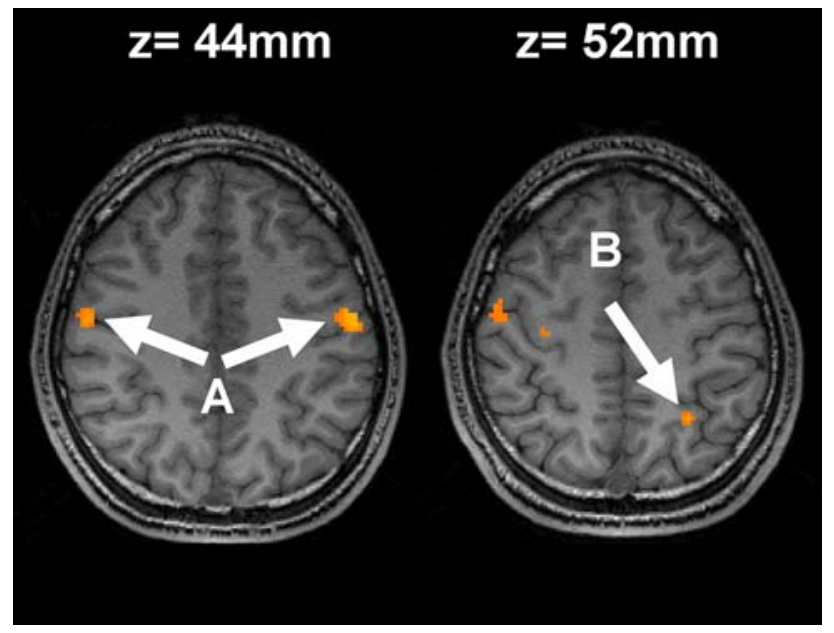

Fig. 3 Voluntary saccade eye movement: activation clusters in the whole brain study for voluntary saccades versus fixation. All areas were thresholded at $P<0.05$ with false discovery rate correction for multiple comparisons and with a minimum cluster size of 10 voxels. (Labels $A$ FEF, $B$ PEF)

1999; Nobre et al. 2000), PEF (Luna et al. 1998; Muri et al. 1998; Berman et al. 1999; Nobre et al. 2000), and the cerebellum (Nobre et al. 2000), as well as in SEF (Luna et al. 1998; Berman et al. 1999), the precuneus (Berman et al. 1999), the cingulate gyrus (Berman et al. 1999; Nobre et al. 2000), MT/V5, PVA/V1 and the midbrain. In general, subjects in these studies were asked to execute saccadic eye movement towards suddenly appearing peripheral targets. In our study, we also found that reflexive saccades yielded activation in the FEF, PEF, MT/V5 and in the angular

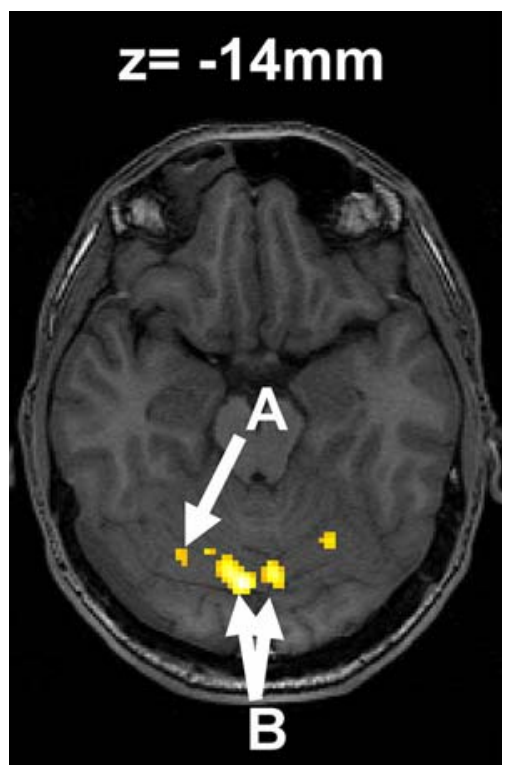

Fig. 4 Voluntary saccades eye movement: activation clusters in the cerebellum study. All areas were thresholded at $P<0.05$ with correction for multiple comparisons at cluster level and with a minimum cluster size of 10 voxels. (Labels $A$ cerebellum lobule VI, $B$ vermis VI and VII)

gyrus, as well as in the cerebellum, more specifically in the cerebellar lobule VI, crus I and in the vermis VI and VII.

For voluntary saccades, PET studies have shown activation in FEF (Fox et al. 1985; Petit et al. 1996; Law et al. 1998), SEF (Fox et al. 1985; Petit et al. 1996; Law et al. 1998), PEF (Petit et al. 1996), PVA/V1 (Fox et al. 1985), the anterior cingulate cortex (Paus et al. 1993), the precuneus (Petit et al. 1996), the midbrain and the cerebellar vermis (Petit et al. 1996; Law et al. 1998). fMRI studies have also shown activation in FEF (Darby et al. 1996; Corbetta et al. 1998), SEF (Darby et al. 1996), PEF, PVA/V1, and the posterior vermis of the cerebellum (Corbetta et al. 1998), as well as in V4. In general, subjects in these studies were asked to execute self-paced voluntary horizontal saccades. In our study, self-paced voluntary saccades yielded activation in the FEF and PEF only, while activation was also found in the cerebellar lobules VI and in the vermis VI and VII.

Taken together, the previous imaging studies suggest a considerable overlap in brain activation during both types of saccadic eye movements. However, direct comparison studies of the brain activation patterns induced by reflexive and voluntary saccades are scarce. So far, only one fMRI study has investigated differences in activation patterns between both types of saccades (Mort et al. 2003). In the latter study, voluntary saccades were evoked by the sudden onset of a central cue indicating the direction of the saccade that was to be made. Using more lenient statistical thresholds than used in our study, the authors reported that, relative to voluntary saccades, the precuneus and the angular 
Table 3 Areas of activation (reflexive saccade > voluntary saccade) with cluster size, maximum $t$ value within the cluster, MNI coordinates of the maximum $t$ value, anatomic labels, percentage of cluster size and functional area

\begin{tabular}{|c|c|c|c|c|c|c|c|c|}
\hline \multicolumn{9}{|c|}{ Whole brain study: reflexive saccade $>$ voluntary saccade } \\
\hline \multirow[t]{2}{*}{ Cluster size } & \multirow[t]{2}{*}{$T$ value } & \multicolumn{3}{|c|}{ MNI coordinate (mm) } & \multirow[t]{2}{*}{ Anatomic area } & \multirow[t]{2}{*}{ side } & \multirow[t]{2}{*}{$\%^{\mathrm{a}}$} & \multirow[t]{2}{*}{ Functional area } \\
\hline & & $x$ & $y$ & $z$ & & & & \\
\hline \multirow[t]{15}{*}{20,691} & \multirow[t]{15}{*}{9.11} & \multirow[t]{15}{*}{46} & \multirow[t]{15}{*}{-60} & \multirow[t]{15}{*}{22} & Middle temporal gyrus & $\mathrm{R}$ & 10.92 & MT/V5 \\
\hline & & & & & Middle temporal gyrus & $\mathrm{L}$ & 9.78 & MT/V5 \\
\hline & & & & & Precuneus & $\mathrm{L}$ & 8.18 & V6 \\
\hline & & & & & Inferior and middle occipital gyrus & $\mathrm{L}$ & 7.47 & PVA/V1 \\
\hline & & & & & Precuneus & $\mathrm{R}$ & 5.83 & V6 \\
\hline & & & & & Angular gyrus & $\mathrm{R}$ & 4.33 & Angular gyrus \\
\hline & & & & & Fusiform gyrus & $\mathrm{L}$ & 3.6 & \\
\hline & & & & & Angular gyrus & $\mathrm{L}$ & 3.58 & Angular gyrus \\
\hline & & & & & Inferior and middle occipital gyrus & $\mathrm{R}$ & 4.49 & PVA/V1 \\
\hline & & & & & Fusiform gyrus & $\mathrm{R}$ & 2.73 & \\
\hline & & & & & $\begin{array}{l}\text { Inferior and superior temporal gyrus, } \\
\text { hippocampal gyrus }\end{array}$ & $\mathrm{R}$ & 7.07 & \\
\hline & & & & & $\begin{array}{l}\text { Inferior temporal gyrus, } \\
\text { parahippocampal gyrus }\end{array}$ & $\mathrm{L}$ & 5.15 & \\
\hline & & & & & Posterior cingulate gyrus & $\mathrm{R}$ & 1.54 & Posterior cingulate gyrus \\
\hline & & & & & Middle cingulate gyrus & $\mathrm{L}$ & 1.3 & \\
\hline & & & & & Lingual gyrus & $\mathrm{R}$ & 1.04 & \\
\hline \multirow[t]{2}{*}{139} & \multirow[t]{2}{*}{4.96} & \multirow[t]{2}{*}{30} & \multirow[t]{2}{*}{-46} & \multirow[t]{2}{*}{64} & Superior and inferior parietal gyrus & $\mathrm{R}$ & 71.95 & PEF \\
\hline & & & & & Post central gyrus & $\mathrm{R}$ & 28.06 & \\
\hline \multirow[t]{3}{*}{277} & \multirow[t]{3}{*}{4.76} & \multirow[t]{3}{*}{32} & \multirow[t]{3}{*}{0} & \multirow[t]{3}{*}{44} & Middle frontal gyrus & $\mathrm{R}$ & 28.16 & \multirow[t]{3}{*}{ FEF } \\
\hline & & & & & Precentral gyrus & $\mathrm{R}$ & 25.99 & \\
\hline & & & & & Inferior opercular frontal gyrus & $\mathrm{R}$ & 19.86 & \\
\hline 918 & 4.5 & -2 & 44 & 20 & Superior middle frontal gyrus & $\mathrm{L}$ & 40.41 & \\
\hline & & & & & Superior middle frontal gyrus & $\mathrm{R}$ & 14.81 & \\
\hline & & & & & Anterior cingulate gyrus & $\mathrm{L}$ & 12.53 & Anterior cingulate gyrus \\
\hline & & & & & Middle orbital frontal gyrus & $\mathrm{R}$ & 10.24 & \\
\hline & & & & & Middle orbital frontal gyrus & $\mathrm{L}$ & 10.02 & \\
\hline & & & & & Anterior cingulate gyrus & $\mathrm{R}$ & 7.19 & Anterior cingulate gyrus \\
\hline 25 & 3.94 & -52 & -62 & 52 & Angular gyrus & $\mathrm{L}$ & 16 & Angular gyrus \\
\hline & & & & & Inferior parietal gyrus & $\mathrm{L}$ & 16 & \\
\hline 77 & 3.73 & -24 & -78 & 54 & Superior and inferior parietal gyrus & $\mathrm{L}$ & 63.63 & PEF \\
\hline 26 & 3.6 & 2 & -36 & 60 & Precuneus & $\mathrm{L}$ & 46.15 & V6 \\
\hline & & & & & Paracentral lobule & $\mathrm{R}$ & 30.77 & \\
\hline & & & & & Paracentral lobule & $\mathrm{L}$ & 3.85 & \\
\hline & & & & & Precuneus & $\mathrm{R}$ & 3.85 & V6 \\
\hline 15 & 3.56 & -6 & 28 & 14 & Anterior cingulate gyrus & $\mathrm{L}$ & 33.33 & Anterior cingulate gyrus \\
\hline 14 & 3.24 & -46 & 16 & 38 & Middle frontal gyrus & $\mathrm{L}$ & 92.86 & FEF \\
\hline & & & & & Precentral gyrus & $\mathrm{L}$ & 7.14 & \\
\hline Cerebellum & tudy: refle & ve sacc & $>$ volu & sacca & & & & \\
\hline 103 & 7.07 & -44 & -44 & -22 & Cerebellum VI & $\mathrm{L}$ & 6.8 & Oculomotor area \\
\hline
\end{tabular}

All areas were thresholded at $P<0.05$ with FDR (whole brain study) or at cluster level $(P<0.05)$ corrected for multiple comparisons (cerebellum study) and with a minimum cluster size of 10 voxels

( $L$ left hemisphere, $R$ right hemisphere, $F E F$ frontal eye fields, $P E F$ parietal eye fields, MT/V5 motion sensitive area (MT/V5), V6 Precuneus, $P V A$ /

$V 1$ primary visual areas (V1)

a The unassigned areas for each cluster are not listed in the table 
Fig. 5 Activation clusters for reflexive versus voluntary saccade eye movement in the whole brain study. All areas were thresholded at $P<0.05$ with false discovery rate correction for multiple comparisons and with a minimum cluster size of 10 voxels. (Labels $A$ FEF, $B$ PEF, $C$ $\mathrm{MT} / \mathrm{V} 5, D$ precuneus, V6, $E$ cingulate gyrus, $F$ angular gyrus)

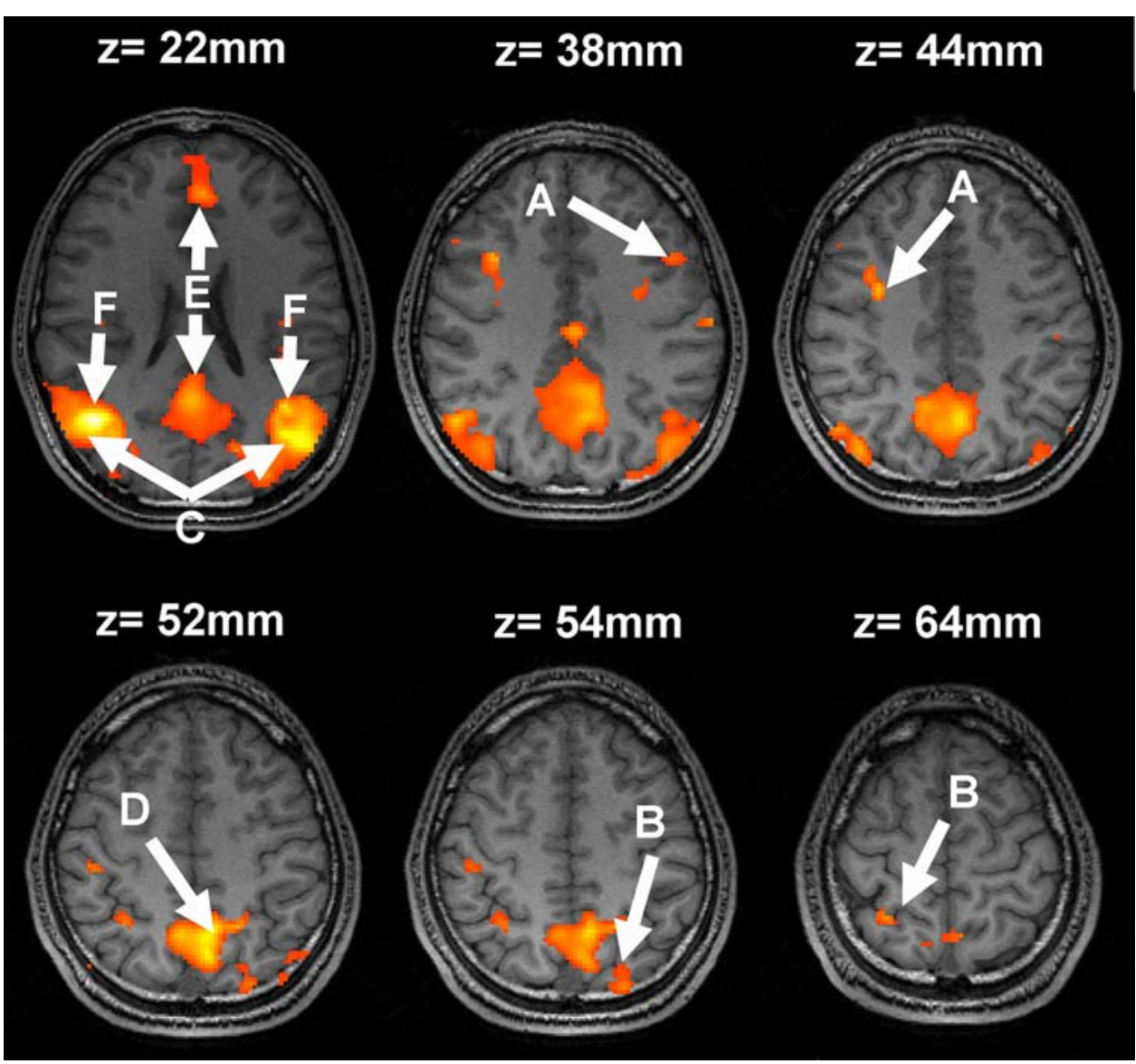

gyri were more strongly activated during reflexive saccades and that, relative to reflexive saccades, FEF and PEF were more strongly activated during voluntary saccades (Mort et al. 2003). In our study it was found that, relative to selfpaced voluntary saccades, the MT/V5, the precuneus, and angular and cingulate gyri were more strongly activated during reflexive saccades. Relative to reflexive saccades, we found no area of interest which was more activated during self-paced voluntary saccades. In the cerebellum we found no significant differences in activation patterns between reflexive and voluntary saccadic eye movements.

Frontal, supplemental and parietal eye fields (FEF, SEF, PEF)

Studies on FEF and SEF lesions in human patients and nonhuman primates suggest that both areas are either not dominantly involved in the generation of reflexive saccades or that damage can be compensated for on a behavioral level by other areas, such as the brainstem (Schiller et al. 1980; van der Steen et al. 1986; Lee and Tehovnik 1995; Sommer and Tehovnik 1997; Schiller and Chou 1998; Dias and Segraves 1999). However, lesions of the PEF in non-human primates (Lynch and McLaren 1989) and humans (Pierrot-
Deseilligny 1991) considerably delay the onset of reflexive saccades, suggesting that the PEF might be more essential than the FEF or SEF for the adequate performance of reflexive saccades (Gaymard et al. 1998).

On the contrary, the contribution of FEF and PEF to voluntary saccades has not been extensively evaluated by lesion studies. Until now, the most studied form of voluntary saccades is the memory-guided saccades (Pierrot-Deseilligny 1991; Rivaud et al. 1994; Sommer and Tehovnik 1997). These studies suggest that unilateral FEF lesions in humans slow down the onset of contralesional memoryguided saccades. Similarly, comparable data on the contribution of PEF to voluntary saccades are scarce as well.

We found that PEF was more activated in reflexive than voluntary saccades, which is in accordance with the lesion studies (Lynch and McLaren 1989; Pierrot-Deseilligny et al. 1991; Gaymard et al. 1998). The PEF is thought to be involved in saccades in terms of visuospatial localization, attention and integration (Pierrot-Deseilligny 1991; Muri 2005). These cognitive processes are likely to be involved in a reflexive saccade condition. At each target onset, the brain needs to attend to it, localize the peripheral target and encode the appropriate spatial directions for the saccadic eye movement towards it (i.e. integration) (Matsuda et al. 
Table 4 A summary of areas of activation in the functional areas of interest for the whole brain and the cerebellum experiments

\begin{tabular}{lllll}
\hline Areas & $\begin{array}{l}\text { Reflexive } \\
\text { saccade }\end{array}$ & $\begin{array}{l}\text { Voluntary } \\
\text { saccade }\end{array}$ & $\begin{array}{l}\text { Reflexive } \\
\text { voluntary }\end{array}$ & $\begin{array}{l}\text { Voluntary } \\
\text { reflexive }\end{array}$ \\
\hline \multicolumn{2}{l}{ Whole brain study } & & & - \\
FEF & B & B & B & - \\
SEF & - & - & - & - \\
PEF & B & L & B & - \\
MT/V5 & B & - & B & - \\
Precuneus/V6 & - & - & B & - \\
Angular gyrus & L & - & B & - \\
Cingulate gyrus & - & - & B & - \\
Cerebellum study & & & - \\
Lobule VI & B & R & - & - \\
Crus I & L & - & - & - \\
Vermis VI & + & + & - & - \\
Vermis VII & + & + & - & - \\
\hline
\end{tabular}

All areas were thresholded at $P<0.05$ with FDR (whole brain study) or at cluster level $(P<0.05)$ corrected for multiple comparisons (cerebellum study) and with a minimum cluster size of 10 voxels

$B$ bilateral, $L$ left hemisphere, $R$ right hemisphere, $F E F$ frontal eye fields, $S E F$ supplementary eye fields, $P E F$ parietal eye fields, MT/V5 motion-sensitive area (MT/V5), $P V A / V 1$ primary visual areas (V1)

+ with significant activation, - no significant activation

2004). In the voluntary condition these processes may have a less prominent role, which might relate to the increased activation in PEF in the reflexive saccade condition.

We also found that the FEF was more activated during the generation of reflexive rather than voluntary saccades, which seems to be at odds with the physiological and functional studies mentioned above. However, it has been proposed that the FEF, which is related to the preparatory stage of saccadic responses, sends out intention and readiness signals to the superior colliculus (Connolly et al. 2002). Since in our paradigm subjects were aware that they were about to make reflexive saccades, the activation in the FEF could reflect such intention and readiness signals.

The increased activation in the FEF and PEF during the generation of reflexive compared to voluntary saccades is in contrast to an earlier study which found that FEF and PEF were more activated during voluntary saccades (Mort et al. 2003). In the latter study eye movement was not recorded during scanning and the number of saccades may not have matched the number of stimuli. In the present study, we recorded the in-scanner behavior and found that the number of saccades in the different active conditions was different. However, adding the number of saccades as a regressor in the fMRI analysis did not change the differences in the activation between reflexive and voluntary saccades. We did not observe any significant activation in the
SEF during saccadic eye movements. Activation in the SEF related to reflexive or voluntary saccade eye movements has been reported by some (Fox et al. 1985; Darby et al. 1996; Petit et al. 1996; Law et al. 1998; Luna et al. 1998; Muri et al. 1998; Berman et al. 1999; Nobre et al. 2000), but not by others (Anderson et al. 1994; Mort et al. 2003).

Motion-sensitive area (MT/V5)

Neurons in the MT area of monkeys are specifically responsive to visual motion, selectively for both direction and speed, and have receptive field sizes of up to $25^{\circ}$ in visual angle (Zeki 1974; Baker et al. 1981; Van Essen et al. 1981; Maunsell and Van Essen 1983; Felleman and Kaas 1984; Churchland and Lisberger 2001). Functional imaging studies in humans have shown that the human homologue, area MT/V5, is also highly responsive to visual motion stimuli (Zeki et al. 1991; Watson et al. 1993; Tootell et al. 1995). We found that MT/V5 was bilaterally more activated in the reflexive than in the voluntary saccade condition, although no real visual motion was present in either condition. This activation could be explained by a phenomenon known as apparent motion (Wertheimer 1912). When two stimuli at two different locations are turned on and off in alternation (as was the case in our reflexive condition), subjects often perceive this as one single stimulus moving between two locations, rather than two stimuli flashing in alternation at the two locations. This percept is absent when the two stimuli are presented simultaneously, as in our voluntary saccade condition. Such a stimulus, in which the apparent motion phenomenon occurs, evokes activation in the human MT/V5 region (Goebel et al. 1998) and in area MT of monkeys (Mikami 1991; Albright 1993), just like a true visual motion stimulus.

Precuneus, cingulate gyrus and angular gyrus

The present study demonstrated that the precuneus, the posterior and anterior cingulate and the angular gyri showed more activation during reflexive and voluntary saccades.

Studies in non-human primates suggest that the precuneus belongs to part of the neural network specialized for the processing of spatially-guided behavior (Selemon and Goldman-Rakic 1988). Functional imaging studies have shown that the precuneus is involved in reflexive saccadic eye movements (Berman et al. 1999) and is associated with shifts of spatial attention (Cavanna and Trimble 2006). The anterior cingulate gyrus is involved in target detection (Posner and Petersen 1990) and is activated during self-paced saccades (Paus et al. 1993; Petit et al. 1996; Sweeney et al. 1996) and during reflexive saccades (Berman et al. 1999; Mort et al. 2003). Neurons in the posterior cingulate cortex of primates fire instantly to assign the spatial coordinates 
after a saccade in which the eye position signals are provided and to permit monitoring of either eye or self motion (Olson et al. 1996). Functional studies have shown that the posterior cingulate cortex is involved in confirming the new target position during reflexive saccades (Mort et al. 2003). Lesion studies show that the main area facilitating the triggering of reflexive visually-guided saccades, but not the voluntary saccades (Cavanna and Trimble 2006), is located in the posterior parietal cortex, in or near the superior part of the angular gyrus (Pierrot-Deseilligny 1991; PierrotDeseilligny et al. 1991).

\section{Cerebellar activation}

The cerebellum plays an important role in the control rather than in the generation of saccadic eye movements. The vermis (VI and VII) are involved in controlling the accuracy and timing of saccades (Noda et al. 1990; Voogd and Barmack 2005).

Microstimulation of vermis VI and VII in the alert monkey induce and influence saccadic eye movements (Ron and Robinson 1973). The Purkinje cells of vermis VI and VII project to the caudal part of the fastigial nucleus, which projects to the vestibular nuclei and saccade-related brainstem nuclei (Noda et al. 1990). Electrophysiological experiments and clinical studies suggest that the vermis VI and VII are involved in the direction-selective control of saccade metrics and in saccadic adaptation (Kase et al. 1980; Suzuki and Keller 1988; Fuchs et al. 1993). Disrupting the posterior vermis, especially area VI, VII and paravermis, in humans using transcranial magnetic stimulation also suggest that these areas are related to the execution of visuallyguided saccades (Hashimoto and Ohtsuka 1995). Lesioning the oculomotor vermis in monkeys leads to a clear shortening of saccades (saccadic hypometria), an increase in saccadic amplitude variability and loss of adaptive capability of saccadic amplitudes (Takagi et al. 1998; Barash et al. 1999). Although hypometria dissolves within a year, saccadic amplitudes remain highly variable (Barash et al. 1999). Saccadic behavior of patients with lesions of the vermis VI and VII suggest that there is a dissociation between the extent of saccadic variability and the lack of adaptive capability (Straube et al. 2001). Indeed, an increased variability in saccadic accuracy does not generally lead to diminished saccadic adaptation (van der Geest et al. 2006). Lesions of the vermis VI and VII and the posterior hemispheres do not only affect saccadic accuracy, but may also delay the covert orientation of visuospatial attention (Townsend et al. 1999).

Several fMRI studies have reported activation of the cerebellum during saccadic eye movements. The cerebellar hemispheres were bilaterally activated during both voluntary (Dieterich et al. 2000) and reflexive saccades (Hayakawa et al. 2002). Activation in vermis VI and VII was observed in reflexive saccades (Hayakawa et al. 2002; Nitschke et al. 2004). Dieterich et al. proposed that vermis IX and lobules IV and V, as well as a small portion of vermis VIII, might be involved in oculomotor performance and the activation of the cerebellar hemispheres could possibly reflect visuospatial attention processes (Dieterich et al. 2000). Nitschke et al. suggested that the vermis VI and VII of the cerebellum play a predominant role in the control of visually-triggered saccadic eye movements, and are involved in processing visuospatial working memory and attention (Nitschke et al. 2004).

In accordance with these previous studies, we also found activation in cerebellar lobule VI and vermis VI and VII, for both types of saccades. However, when we compared the two types of saccades directly, no significant difference in activation was found. So, although the cerebellum is thought to be critically involved in saccade amplitude modifications in humans (Desmurget et al. 1998; Straube et al. 2001), the lack of transfer between the adaptation of reflexive and voluntary saccades as observed in behavioral studies (Erkelens and Hulleman 1993; Gaveau et al. 2005; Alahyane et al. 2007) is not reflected by differences in cerebellar activation between the two types of saccades. There are two possible, and not mutually exclusive, explanations for the lack of differential activation. It is possible that the modification of amplitudes of the two types of saccades is processed by different sets of neurons within the same cerebellar regions. Alternatively or additionally, the lack of transfer between voluntary and reflexive saccade adaptation arises on a cerebral level.

In the present experiments, voluntary saccades were self-paced saccades made between two targets. The present paradigm was chosen to mimic the saccadic adaptation experiments in which voluntary and reflexive saccades were dissociated with respect to their amplitude modifications. However, compared to other voluntary eye movement tasks (such as antisaccades and memory-guided saccades), the present task does not engage cognitive processes of inhibitory control and working memory which would recruit frontal areas. Hence, the lack of findings in these regions is not entirely unexpected. Moreover, subjects are able to actively suppress a reflexive saccade using cognitive processes of inhibition. It can be argued that the presently observed differences in circuitry between voluntary and reflexive saccades are mainly related to a self-paced mechanism which is, in our view, still volitional in nature.

\section{Conclusion}

The execution of reflexive saccades induced stronger activation in several cerebral areas, but not in the cerebellum, than the execution of self-paced voluntary saccades. This 
could indicate that functional difference in maintaining the accuracy of the two types of saccades is mediated on a cerebral level, or that it involves overlapping cerebellar regions with possible functional differences.

Acknowledgments The authors thank Dr. Tom Ruigrok for his assistance in anatomical localization of cerebellar fMRI activation.

Open Access This article is distributed under the terms of the Creative Commons Attribution Noncommercial License which permits any noncommercial use, distribution, and reproduction in any medium, provided the original author(s) and source are credited.

\section{References}

Alahyane N, Salemme R, Urquizar C, Cotti J, Guillaume A, Vercher JL, Pelisson D (2007) Oculomotor plasticity: are mechanisms of adaptation for reactive and voluntary saccades separate? Brain Res 1135:107-121

Albright TD (1993) Cortical processing of visual motion. Rev Oculomot Res 5:177-201

Amlot R, Walker R (2006) Are somatosensory saccades voluntary or reflexive? Exp Brain Res 168:557-565

Anderson TJ, Jenkins IH, Brooks DJ, Hawken MB, Frackowiak RS, Kennard C (1994) Cortical control of saccades and fixation in man. A PET study. Brain 117(Pt 5):1073-1084

Baker JF, Petersen SE, Newsome WT, Allman JM (1981) Visual response properties of neurons in four extrastriate visual areas of the owl monkey (Aotus trivirgatus): a quantitative comparison of medial, dorsomedial, dorsolateral, and middle temporal areas. J Neurophysiol 45:397-416

Barash S, Melikyan A, Sivakov A, Zhang M, Glickstein M, Thier P (1999) Saccadic dysmetria and adaptation after lesions of the cerebellar cortex. J Neurosci 19:10931-10939

Berman RA, Colby CL, Genovese CR, Voyvodic JT, Luna B, Thulborn KR, Sweeney JA (1999) Cortical networks subserving pursuit and saccadic eye movements in humans: an FMRI study. Hum Brain Mapp 8:209-225

Cavanna AE, Trimble MR (2006) The precuneus: a review of its functional anatomy and behavioural correlates. Brain 129:564583

Churchland MM, Lisberger SG (2001) Shifts in the population response in the middle temporal visual area parallel perceptual and motor illusions produced by apparent motion. J Neurosci 21:9387-9402

Connolly JD, Goodale MA, Menon RS, Munoz DP (2002) Human fMRI evidence for the neural correlates of preparatory set. Nat Neurosci 5:1345-1352

Corbetta M, Akbudak E, Conturo TE, Snyder AZ, Ollinger JM, Drury HA, Linenweber MR, Petersen SE, Raichle ME, Van Essen DC, Shulman GL (1998) A common network of functional areas for attention and eye movements. Neuron 21:761-773

Darby DG, Nobre AC, Thangaraj V, Edelman R, Mesulam MM, Warach S (1996) Cortical activation in the human brain during lateral saccades using EPISTAR functional magnetic resonance imaging. Neuroimage 3:53-62

Desmurget M, Pelisson D, Urquizar C, Prablanc C, Alexander GE, Grafton ST (1998) Functional anatomy of saccadic adaptation in humans. Nat Neurosci 1:524-528

Desmurget M, Pelisson D, Grethe JS, Alexander GE, Urquizar C, Prablanc C, Grafton ST (2000) Functional adaptation of reactive saccades in humans: a PET study. Exp Brain Res 132:243259
Deubel H (1995) Separate adaptive mechanisms for the control of reactive and volitional saccadic eye movements. Vision Res 35:35293540

Dias EC, Segraves MA (1999) Muscimol-induced inactivation of monkey frontal eye field: effects on visually and memory-guided saccades. J Neurophysiol 81:2191-2214

Dieterich M, Bucher SF, Seelos KC, Brandt T (2000) Cerebellar activation during optokinetic stimulation and saccades. Neurology $54: 148-155$

Erkelens CJ, Hulleman J (1993) Selective adaptation of internally triggered saccades made to visual targets. Exp Brain Res 93:157-164

Felleman DJ, Kaas JH (1984) Receptive-field properties of neurons in middle temporal visual area (MT) of owl monkeys. J Neurophysiol 52:488-513

Fox PT, Fox JM, Raichle ME, Burde RM (1985) The role of cerebral cortex in the generation of voluntary saccades: a positron emission tomographic study. J Neurophysiol 54:348-369

Friston KJ, Frith CD, Frackowiak RS, Turner R (1995) Characterizing dynamic brain responses with fMRI: a multivariate approach. Neuroimage 2:166-172

Fuchs AF, Robinson FR, Straube A (1993) Role of the caudal fastigial nucleus in saccade generation I. Neuronal discharge pattern. J Neurophysiol 70:1723-1740

Gaveau V, Alahyane N, Salemme R, Desmurget M (2005) Self-generated saccades do not modify the gain of adapted reactive saccades. Exp Brain Res 162:526-531

Gaymard B, Ploner CJ, Rivaud S, Vermersch AI, Pierrot-Deseilligny C (1998) Cortical control of saccades. Exp Brain Res 123:159163

Goebel R, Khorram-Sefat D, Muckli L, Hacker H, Singer W (1998) The constructive nature of vision: direct evidence from functional magnetic resonance imaging studies of apparent motion and motion imagery. Eur J NeuroSci 10:1563-1573

Hashimoto M, Ohtsuka K (1995) Transcranial magnetic stimulation over the posterior cerebellum during visually guided saccades in man. Brain 118(Pt 5):1185-1193

Hayakawa Y, Nakajima T, Takagi M, Fukuhara N, Abe H (2002) Human cerebellar activation in relation to saccadic eye movements: a functional magnetic resonance imaging study. Ophthalmologica 216:399-405

Kase M, Miller DC, Noda H (1980) Discharges of Purkinje cells and mossy fibres in the cerebellar vermis of the monkey during saccadic eye movements and fixation. J Physiol 300:539-555

Law I, Svarer C, Rostrup E, Paulson OB (1998) Parieto-occipital cortex activation during self-generated eye movements in the dark. Brain 121(Pt 11):2189-2200

Lee K, Tehovnik EJ (1995) Topographic distribution of fixation-related units in the dorsomedial frontal cortex of the rhesus monkey. Eur J NeuroSci 7:1005-1011

Leigh RJ, Zee DS (1999) The neurology of eye movements. Oxford University Press, New York

Luna B, Thulborn KR, Strojwas MH, McCurtain BJ, Berman RA, Genovese CR, Sweeney JA (1998) Dorsal cortical regions subserving visually guided saccades in humans: an fMRI study. Cereb Cortex 8:40-47

Lynch JC, McLaren JW (1989) Deficits of visual attention and saccadic eye movements after lesions of parietooccipital cortex in monkeys. J Neurophysiol 61:74-90

Matsuda T, Matsuura M, Ohkubo T, Ohkubo H, Matsushima E, Inoue K, Taira M, Kojima T (2004) Functional MRI mapping of brain activation during visually guided saccades and antisaccades: cortical and subcortical networks. Psychiatry Res 131:147-155

Maunsell JH, Van Essen DC (1983) Functional properties of neurons in middle temporal visual area of the macaque monkey. I. Selectivity for stimulus direction, speed, and orientation. J Neurophysiol 49:1127-1147 
McLaughlin SC (1967) Parametric adjustment in saccadic eye movements. Percept Psychophys 2:359-362

Mikami A (1991) Direction selective neurons respond to short-range and long-range apparent motion stimuli in macaque visual area MT. Int J Neurosci 61:101-112

Mort DJ, Perry RJ, Mannan SK, Hodgson TL, Anderson E, Quest R, McRobbie D, McBride A, Husain M, Kennard C (2003) Differential cortical activation during voluntary and reflexive saccades in man. Neuroimage 18:231-246

Muri RM (2005) MRI and fMRI analysis of oculomotor function. Prog Brain Res 151:503-526

Muri RM, Heid O, Nirkko AC, Ozdoba C, Felblinger J, Schroth G, Hess CW (1998) Functional organisation of saccades and antisaccades in the frontal lobe in humans: a study with echo planar functional magnetic resonance imaging. J Neurol Neurosurg Psychiatry 65:374-377

Nitschke MF, Binkofski F, Buccino G, Posse S, Erdmann C, Kompf D, Seitz RJ, Heide W (2004) Activation of cerebellar hemispheres in spatial memorization of saccadic eye movements: an fMRI study. Hum Brain Mapp 22:155-164

Nobre AC, Gitelman DR, Dias EC, Mesulam MM (2000) Covert visual spatial orienting and saccades: overlapping neural systems. Neuroimage 11:210-216

Noda H, Sugita S, Ikeda Y (1990) Afferent and efferent connections of the oculomotor region of the fastigial nucleus in the macaque monkey. J Comp Neurol 302:330-348

Olson CR, Musil SY, Goldberg ME (1996) Single neurons in posterior cingulate cortex of behaving macaque: eye movement signals. J Neurophysiol 76:3285-3300

Paus T, Petrides M, Evans AC, Meyer E (1993) Role of the human anterior cingulate cortex in the control of oculomotor, manual, and speech responses: a positron emission tomography study. J Neurophysiol 70:453-469

Petit L, Orssaud C, Tzourio N, Crivello F, Berthoz A, Mazoyer B (1996) Functional anatomy of a prelearned sequence of horizontal saccades in humans. J Neurosci 16:3714-3726

Petit L, Clark VP, Ingeholm J, Haxby JV (1997) Dissociation of saccade-related and pursuit-related activation in human frontal eye fields as revealed by fMRI. J Neurophysiol 77:3386-3390

Pierrot-Deseilligny C (1991) Cortical control of saccades in man. Acta Neurol Belg 91:63-79

Pierrot-Deseilligny C, Rivaud S, Gaymard B, Agid Y (1991) Cortical control of reflexive visually-guided saccades. Brain $114(\mathrm{Pt}$ 3):1473-1485

Posner MI, Petersen SE (1990) The attention system of the human brain. Annu Rev Neurosci 13:25-42

Rivaud S, Muri RM, Gaymard B, Vermersch AI, Pierrot-Deseilligny C (1994) Eye movement disorders after frontal eye field lesions in humans. Exp Brain Res 102:110-120

Ron S, Robinson DA (1973) Eye movements evoked by cerebellar stimulation in the alert monkey. J Neurophysiol 36:1004-1022

Schall JD (1995) Neural basis of saccade target selection. Rev Neurosci 6:63-85

Schiller PH, Chou IH (1998) The effects of frontal eye field and dorsomedial frontal cortex lesions on visually guided eye movements. Nat Neurosci 1:248-253

Schiller PH, Tehovnik EJ (2005) Neural mechanisms underlying target selection with saccadic eye movements. Prog Brain Res 149:157171

Schiller PH, True SD, Conway JL (1980) Deficits in eye movements following frontal eye-field and superior colliculus ablations. J Neurophysiol 44:1175-1189

Selemon LD, Goldman-Rakic PS (1988) Common cortical and subcortical targets of the dorsolateral prefrontal and posterior parietal cortices in the rhesus monkey: evidence for a distributed neural network subserving spatially guided behavior. J Neurosci 8:4049-4068

Sommer MA, Tehovnik EJ (1997) Reversible inactivation of macaque frontal eye field. Exp Brain Res 116:229-249

Straube A, Deubel H (1995) Rapid gain adaptation affects the dynamics of saccadic eye movements in humans. Vision Res 35:34513458

Straube A, Deubel H, Ditterich J, Eggert T (2001) Cerebellar lesions impair rapid saccade amplitude adaptation. Neurology 57:21052108

Suzuki DA, Keller EL (1988) The role of the posterior vermis of monkey cerebellum in smooth-pursuit eye movement control II. Target velocity-related Purkinje cell activity. J Neurophysiol 59:19_ 40

Sweeney JA, Mintun MA, Kwee S, Wiseman MB, Brown DL, Rosenberg DR, Carl JR (1996) Positron emission tomography study of voluntary saccadic eye movements and spatial working memory. J Neurophysiol 75:454-468

Takagi M, Zee DS, Tamargo RJ (1998) Effects of lesions of the oculomotor vermis on eye movements in primate: saccades. J Neurophysiol 80:1911-1931

Tootell RB, Reppas JB, Kwong KK, Malach R, Born RT, Brady TJ, Rosen BR, Belliveau JW (1995) Functional analysis of human MT and related visual cortical areas using magnetic resonance imaging. J Neurosci 15:3215-3230

Townsend J, Courchesne E, Covington J, Westerfield M, Harris NS, Lyden P, Lowry TP, Press GA (1999) Spatial attention deficits in patients with acquired or developmental cerebellar abnormality. $\mathrm{J}$ Neurosci 19:5632-5643

Tzourio-Mazoyer N, Landeau B, Papathanassiou D, Crivello F, Etard O, Delcroix N, Mazoyer B, Joliot M (2002) Automated anatomical labeling of activations in SPM using a macroscopic anatomical parcellation of the MNI MRI single-subject brain. Neuroimage 15:273-289

van der Geest JN, Haselen GC, Frens MA (2006) Saccade adaptation in Williams-Beuren Syndrome. Invest Ophthalmol Vis Sci 47:1464-1468

van der Steen J, Russell IS, James GO (1986) Effects of unilateral frontal eye-field lesions on eye-head coordination in monkey. J Neurophysiol 55:696-714

Van Essen DC, Maunsell JH, Bixby JL (1981) The middle temporal visual area in the macaque: myeloarchitecture, connections, functional properties and topographic organization. J Comp Neurol 199:293-326

Voogd J, Barmack NH (2005) Oculomotor cerebellum. Prog Brain Res 151:231-268

Walker R, Walker DG, Husain M, Kennard C (2000) Control of voluntary and reflexive saccades. Exp Brain Res 130:540-544

Watson JD, Myers R, Frackowiak RS, Hajnal JV, Woods RP, Mazziotta JC, Shipp S, Zeki S (1993) Area V5 of the human brain: evidence from a combined study using positron emission tomography and magnetic resonance imaging. Cereb Cortex 3:79-94

Wertheimer M (1912) Experimentelle Studien uber das Sehen von Bewegung. Zeitschrift fur Psychologie 61:161-265

Zee DS, Optican LM, Cook JD, Robinson DA, Engel WK (1976) Slow saccades in spinocerebellar degeneration. Arch Neurol 33:243251

Zeki S, Watson JD, Lueck CJ, Friston KJ, Kennard C, Frackowiak RS (1991) A direct demonstration of functional specialization in human visual cortex. J Neurosci 11:641-649

Zeki SM (1974) Functional organization of a visual area in the posterior bank of the superior temporal sulcus of the rhesus monkey. $\mathrm{J}$ Physiol 236:549-573 